BNL 50755
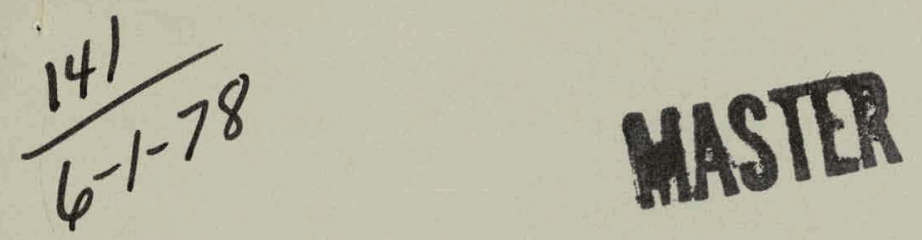

\title{
HYDROGEN ISOTOPE EXCHANGE IN METAL HYDRIDE COLUMNS
}

R. Wiswall, J. Reilly, F. Bloch, and E. Wirsing

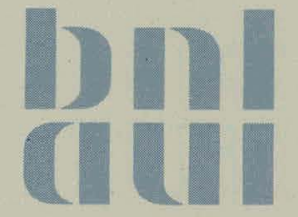

November 21, 1977

CHEMICAL SCIENCES DIVISION

DEPARTMENT OF ENERGY AND ENVIRONMENT

BROOKHAVEN NATIONAL LABORATORY

ASSOCIATED UNIVERSITIES, INC.

UNDER CONTRACT NO. EY-76-C-02-0016 WITH THE

UNITED STATES DEPARTMENT OF ENERGY 


\section{DISCLAIMER}

This report was prepared as an account of work sponsored by an agency of the United States Government. Neither the United States Government nor any agency Thereof, nor any of their employees, makes any warranty, express or implied, or assumes any legal liability or responsibility for the accuracy, completeness, or usefulness of any information, apparatus, product, or process disclosed, or represents that its use would not infringe privately owned rights. Reference herein to any specific commercial product, process, or service by trade name, trademark, manufacturer, or otherwise does not necessarily constitute or imply its endorsement, recommendation, or favoring by the United States Government or any agency thereof. The views and opinions of authors expressed herein do not necessarily state or reflect those of the United States Government or any agency thereof. 


\section{DISCLAIMER}

Portions of this document may be illegible in electronic image products. Images are produced from the best available original document. 
BNL 50755

UC-22

(Isotope Separation - TID-4500)

\title{
HYDROGEN ISOTOPE EXCHANGE IN METAL HYDRIDE COLUMNS
}

\author{
R. Wiswall, J. Reilly, F. Bloch, and E. Wirsing
}

November 21, 1977

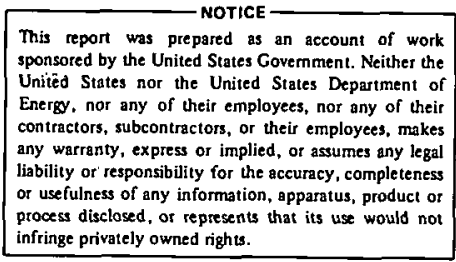

Research sponsored by the DIVISION OF BASIC ENERGY SCIENCES

U.S. DEPARTMENT OF ENERGY WASHINGTON, D.C.

CHEMICAL SCIENCES DIVISION

DEPARTMENT OF ENERGY AND ENVIRONMENT

BROOKHAVEN NATIONAL LABORATORY UPTON, NEW YORK 11973 
NOTIOLi

This report was prepared as an account of work sponsored by the United States Government. Neither the United States nor the United States Department of Energy (DOE), nur any of their empluyees, nur any of thelr contractors, subcontractors, or their employees, makes any warranty, express or implied, or assumes any legal liability or responsibility for the accuracy, completeness or usefulness of any information, apparatus, product or process disclosed, or represents that its use would not infringe privately owned rights.

Printed in the United States of America

Available from

National Technical Information Service

U.S. Department of Commerce

5285 Port Royal Road

Springfield, VA 22161

Price: Printed Copy $\$ 4.50$; Microfiche $\$ 3.00$

March 1978

230 copies 
TABLE OF CONTENTS

Summary

I. Introduction $\quad 1$

II. Hydrides and the Chromatographic Process. 1

III. Results of Experiments : : . . . . 3

A. Vanadium 3

1. Breakthrough Experiments 7

2. Band Experiments ... 10

3. Effect of Particle Size 12

4. Effect of Flow Rate : 13

5. Effect of Temperature . 13

6. Effect of Solid Composition 14

7. Best Runs $\because . \quad 14$

B. Other Hydrides 15

1. LaNi 515

2. $\mathrm{MmNi}_{5} \quad 19$

3. $\mathrm{Mg}_{2} \mathrm{Ni} \quad 20$

4. Zirconium . 20

5. Comparison of Systems. . 23

C. Dual-Temperature Experiments $\quad 23$

T.V. References $\quad 31$ 


\section{SUMMARY}

Several metal hydrides were shown to act as chromatographic media for hydrogen isotopes. The procedure was to equilibrate a column of hydride with flowing hydrogen, inject a small quantity of tritium tracer, and observe its elution behavior. Characteristic retention times were found. From these and the extent of widening of the tritium band, the heights equivalent to a theoretical plate could be calculated. Values of around $1 \mathrm{~cm}$ were obtained. The following are the metals whose hydrides were studied, together with the temperature ranges in which chromatographic behavior was observed: vanadium, $0^{\circ}$ to $70^{\circ} \mathrm{C}$; zirconium, $500^{\circ}$ to $600^{\circ} \mathrm{C}$; $\mathrm{LaNi}_{5} ;-78^{\circ}$ to $+30^{\circ} \mathrm{C} ; \mathrm{Mg}_{2} \mathrm{Ni}$, $300^{\circ}$ to $375^{\circ} \mathrm{C}$; palladium, $0^{\circ}$ to $70^{\circ} \mathrm{C}$.

A dual-temperature isotope separation process based on hydride chromatography was demonstrated. In this, a column was caused to cycle between two temperatures while being supplied with a constant stream of tritium-traced hydrogen. Each half-cycle was continued until "breakthrough," i.e., until the tritium concentration in the effluent was the same as that in the feed. Up to that point, the effluent was enriched or depleted in tritium, by up to $20 \%$. 


\section{INTRODUCTION}

This report describes a series: of experiments that were carried out to explore practical ways of using metal hydrides for the separation of hydrogen isotopes. Many hydrides show large isotope effects, in that the dissociation pressure of the deuteride differs from that of the protide by a factor of two or more. The direction of the effect varies; most deuterides are less stable than the corresponding protides; but some are more stable. The magnitude of the effect usually is strongly temperature dependent.

In previous work from this laboratory, ${ }^{1}$ isotope effects were determined for a number of systems. Some of these appeared sufficiently interesting with respect to magnitude, direction, and temperature coefficient to be worth exploring as practical media for hydrogen isotope separation. A novel and superior separation process could have many applications, e.g., tritium scavenging from nuclear power wastes, analytical procedures, deuterium production, and use in the tritium cycle of thermonuclear reactors.

The metal hydrides of interest were used as substrates in chromatographic columns, for reasons discussed in the next section. A large number of experiments were done, and their results are summarized below. The work, done mostly in 1972 and 1973, remains incomplete, but it seemed best to delay no longer in getting it on record. This account may be useful if research in this field is resumed.

Some of the data published here were used by $R$. Benenati for process deeign etudies on 3 plant to decontaminate tritiated water. ${ }^{2}$

\section{HYDRIDES AND THE CHROMATOGRAPHIC PROCESS}

The resolution of fluid mixtures by selective absorption in, or adsorption on, a solid is best effected by some variant of the chromatographic process. In the simplest case of this, the mixture is caused to pass through a bed of absorbent under conditions" such that a reiatively labile association occurs between the solid and each component of the mixture. The more strongly absorbed components are retarded relative to the less strongly absorbed. Each 
emerges from the bed, after repeated absorptions and desorptions, at a characteristic time and can be isolated. In one method, all the active components are absorbed together from an inert matrix or solvent and later removed, in chromatographic succession, by an eluting fluid. More sophisticated procedures may involve varying the temperature in time or space to increase the resolution.:

Chromatographic separations of hydrogen isotopes have been demonstrated for a number of substrates..$^{3-5}$ On some substrates, like $\mathrm{Al}_{2} \mathrm{O}_{3}$, the interaction was an adsorption; with others, like Pd and $U$, the hydrogen formed a transitory alloy or compound. Palladlum has been the subject of the largest amount of such research. A particularly thorough investigation was done by Glueckauf and Kitt, ${ }^{4,5}$ who used columns packed with palladium black supported on asbestos. Three different procedures were tried: (a) Breakthrough experiments, in which a mixture of $\mathrm{H}_{2}$ and $\mathrm{D}_{2}$ was fed continuously to the inlet of a column. The first gas to emerge was nearly pure deuterium. (b) Displacement experiments, in which a limited quantity of a $\mathrm{H}_{2}-\mathrm{D}_{2}$ mixture was absorbed on a column and then eluted by a stream of normal hydrogen. A large fraction of the deuterium came off in nearly pure form. (c) A similar experiment in which the displacement of absorbed gas was accomplished, not by an eluant, but by progressive heating of the column from the rear. In a typical run in which the starting mixture contained $40.69 \%$ deuterium, $93 \%$ of the deuterium was recovered in the front band, which analyzed $97.49 \%$ deuterium. Good results were also obtained with lower entering compositions. This work did not lead to the development of a practical isotope separation process because of. the high cost of palladium. It seemed to us, however, that the principle involved was a useful one, and that if a cheaper metal were found to behave like palladium a new commercial process might result.

In the procedures described so far, the absorbing bed material in its normal state was unreacted metal, the formation of hydride being transitory and possibly limited to surface layers. In another system for exploiting a hydride isotope effect chromatographically the substrate is in the hydride form throughout, and separation is caused by exchange rather than by a 
hydride formation-decomposition cycle. Consider, for example, a column of metal hydride into which hydrogen containing a trace of tritium is being fed. Isotopic exchange is assumed to take place fast enough that the length of a "theoretical plate" is short compared with the length of the column. The exchange will result in transfer of tritium to the solid and the production of a quantity of tritium-free hydrogen. Eventually, of course, tritium will appear in the effluent; at this "breakthrough" point, the tritiumprotium ratio in the solid hydride phase will be greater or less than that in the entering gas, depending on the value of the separation factor, defined below. A unit process of this sort can obviously be incorporated into a multistage separation plant.

The situation is especially advantageous if the separation factor is a sensitive function of temperature. In such a case, if the exchanging column is alternated between two temperatures while a constant isotopic mixture is fed in, the two effluent streams will differ, one being higher in a given isotope than the influent stream and the other lower.

\section{RESULTS OF EXPERTMENTS}

\section{A. Vanadium}

The bulk of our chromatographic runs, and all the development of technique, were carried out with vanadium. Vanadium hydride had earlier been found to have a large equilibrium isotope effect, ${ }^{1}$ which is defined quantitatively in terms of $\alpha$, the separation factor:

$$
\begin{aligned}
& \alpha_{d p} \equiv \frac{(d / p)_{s}}{(d / p)_{g}}, \\
& \alpha_{t p} \equiv \frac{(t / p)_{s}}{(t / p)_{g}},
\end{aligned}
$$

where $p, d$, and $t$ are the concentrations of protium, deuterium, and tritium, and the subscripto $\mathrm{a}$ and $g$ refer to solin. phase and gas phase. Some values of $\alpha$ for $V, P d$, and $U$ are plotted against reciprocal temperature in Figure 1. The vanadium $\alpha$ can be seen to have an appreciable temperature coefficient. 


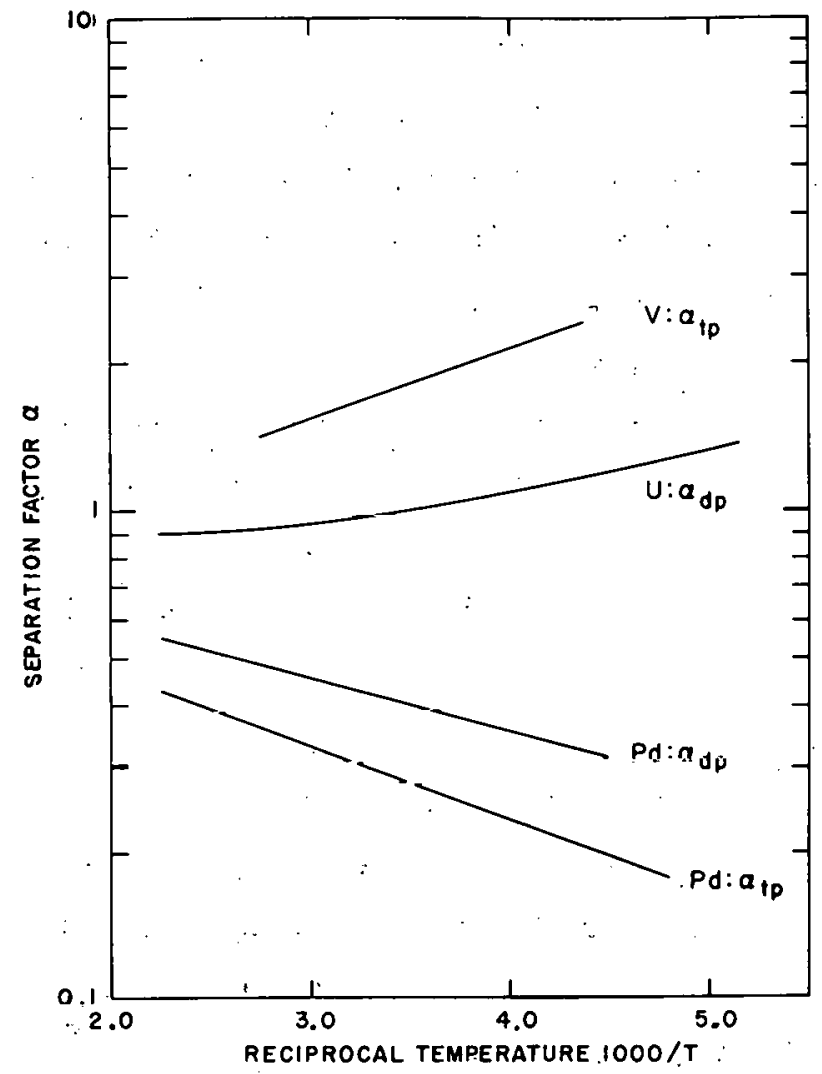

Figure 1. Equilibrium isotope separation factors in metal-hydrogen systems. (Data sources: vanadiuml; uranium ${ }^{6} ; \alpha_{d p}$ for palladium; $\alpha_{t p}$ for palladium from data ${ }^{7}$ converted by the equation 8 in $\alpha_{t p}=1.4$ in $\alpha_{d p}$.)

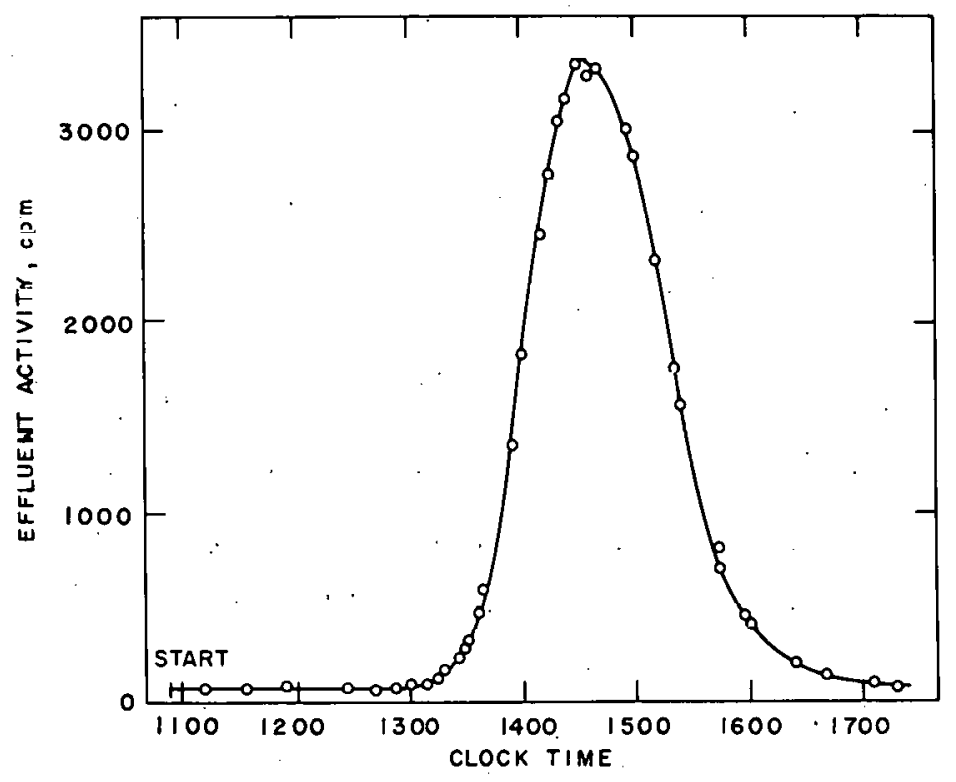

in

Figure 2. Elution of tritium from vanadium hydride, run No. 33. 


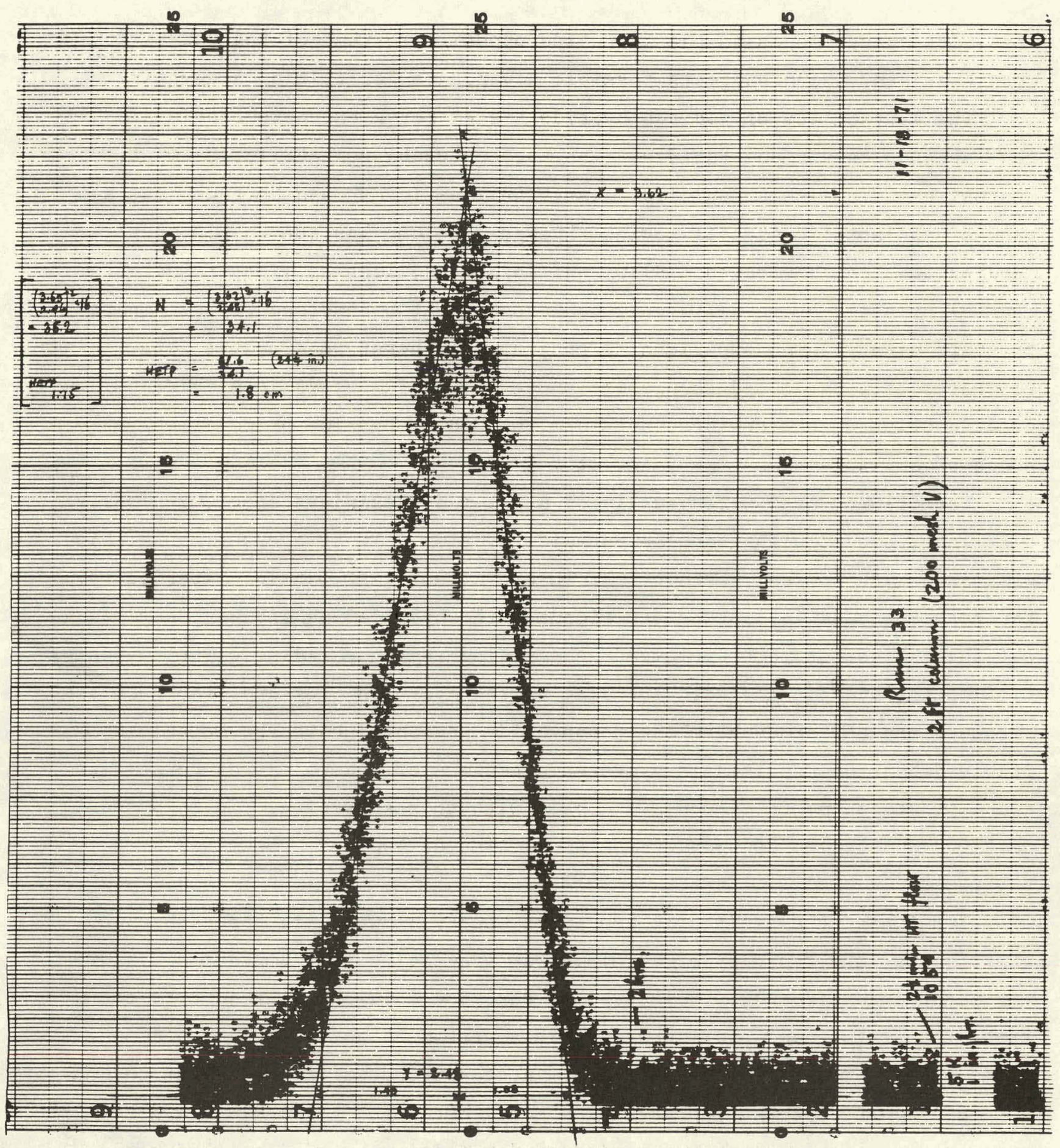

Figure 3. Elution of tritium from vanadium hydride, strip-chart record of run No. 33 . 
Also, its curve slopes in the direction opposite to that of the curves for most hydrides, which suggests possible advantages for tritium scavenging. The suitability of a given hydride system for a chromatographic process depends on various factors. The isotope exchange equilibrium must, of course, be established rapidly. Also, the kinetics should be such that a band of an isotopic species moving through a column has reasonably sharp leading and trailing edges. Slow equilibrations, such as might result from control by solid-state diffusion, could smear out a band and reduce separation efficiency. The experimental program was therefore aimed at determining the rates of passage and changes of shape of tritium bands in hydride columns, as a function of temperature, pressure, method of hydride preparation, presence of diluents, gas flow rate, etc.

The columns used were usually of $\frac{1}{4}-i n .-o . d$. stainless steel, typically $3 \mathrm{ft}$ long, packed with granular vanadium hydride. In some experiments thís was mixed with several parts of Chromosorb A, an inert packing material. Before being used in isotope experiments, the hydride was activated by being put through one or more cycles of dehydriding and rehydriding. The composition of the hydride varied, depending on the hydrogen pressure. At room temperature and one atmosphere the monohydride was obtained. The much less stable dihydride resulted if hydrogen pressures of several atmospheres were applied, and a number of runs were made with this substrate. In this connection, a detailed account of the properties of the $\mathrm{V}-\mathrm{H}$ system has been published. 15

Two types of experimental procedure were followed. In "breakthrough" experiments, the capacity of a column for scavenging tritium from a mixture was determined directly. In a typical run, the column was brought to constant temperature and equilibrated with a stream of pure hydrogen. Flow rates were in the range of $35 \mathrm{cc} / \mathrm{min}$. At $t=0$ the gas entering the column was replaced by hydrogen containing a trace amount of tritium. The gas stream leaving the column was monitored for tritium by mixing it with ten parts of $\mathrm{P}-10$ counting gas and passing it through an internal proportional counter. Tritium disintegrations were registered on standard counting 
equipment. Our practice was both to take frequent one-minute counts "by hand" and also to use the equipment in the rate-meter mode to provide a continuous print-out of the effluent activity on a strip chart. Figures 2 and 3 illustrate the two ways of graphing the results. Note that in Figure 3 the time increases from right to left.

It proved, however, that: more information could be obtained from studies of the behavior of a narrow band of heavy isotope. In these "band" experiments, a smal1 quantity of more concentrated tritium-protium mixture was injected over a very short time interval (at: first, minutes; later, seconds) into the hydrogen stream entering the column. The activity passed through the column in the form of a narrow band and was registered as such at the outlet.

\section{Breakthrough Experiments}

The kind of information given by this series is best illustrated by Figure 4, which is a graph of activity vs. time obtained in one of our better vanadium runs, No. 64. The conditions were as follows: column dimensions, $2 \mathrm{ft} \times \frac{1}{4}$-in.-o.d.; loading, $23 \mathrm{~g}$ commercial vanadium (Union Carbide) of mesh size $-10+20$, converted to the monohydride $\left(\mathrm{VH}_{20.8}\right)$; temperature, $30.0^{\circ}$ to $30.5^{\circ} \mathrm{C}$; pressure, $36.4 \mathrm{psia}$; flow rate, $35 \mathrm{cc} / \mathrm{min}$ (at STP). The ordinate shows observed counts per minute, which, as can be seen, remained at background level for about $2 \frac{1}{4} \mathrm{hr}$ after the tritium-traced mixture began to enter the column. In other words, some 4.7 liters were completely purified of. tritium. That this was due to a genuine chromatographic effect can be seen by calculating the transit time through the column of an element of gas which did not interact with the solid. From the flow rate and an estimated dead volume for the column and associated tubing of about $15 \mathrm{cc}$, the transit time comes to about half a minute. This was experimentally confirmed in a separate experiment, by determining the transit time of a small quantity of krypton-85.

It can be calculated from the vanadium content of the column and the total hydrogen emerging before breakthrough that the latter was about equal in mass to the hydrogen in the solid phase. It follows that the 
chromatographically active vanadium hydride was not limited to surface layers but comprised the entire charge, and that solid-state diffusion of the hydrogen isotope was not limiting.

Further inspection of Figure 4 shows that saturation of the column with respect to tritium occurred about $4 \frac{1}{4} \mathrm{hr}$ after the start. Shortly thereafter, at 1416, the inflowing tritium-traced gas was replaced with hydrogen, and the tracer began to be displaced from the vanadium hydride into the gas. The activity level in the outflow remained constant until about 1630, again $2 \frac{1}{4} \mathrm{hr}$. Then the activity began its descent along a curve approximately the inverse of the rising portion, with the final portion (not shown in Figure 4) showing the gas back at background activity. No net isotope separation results from a cyclic isothermal process such as this, but a half-cycle can be used in a stage of a two-temperature separation process, as described later.

The suitability of a particular column and set of operating conditions can be judged (a) by the total exchange capacity and (b) by the sharpness of the moving front that becomes established between tritium-traced and

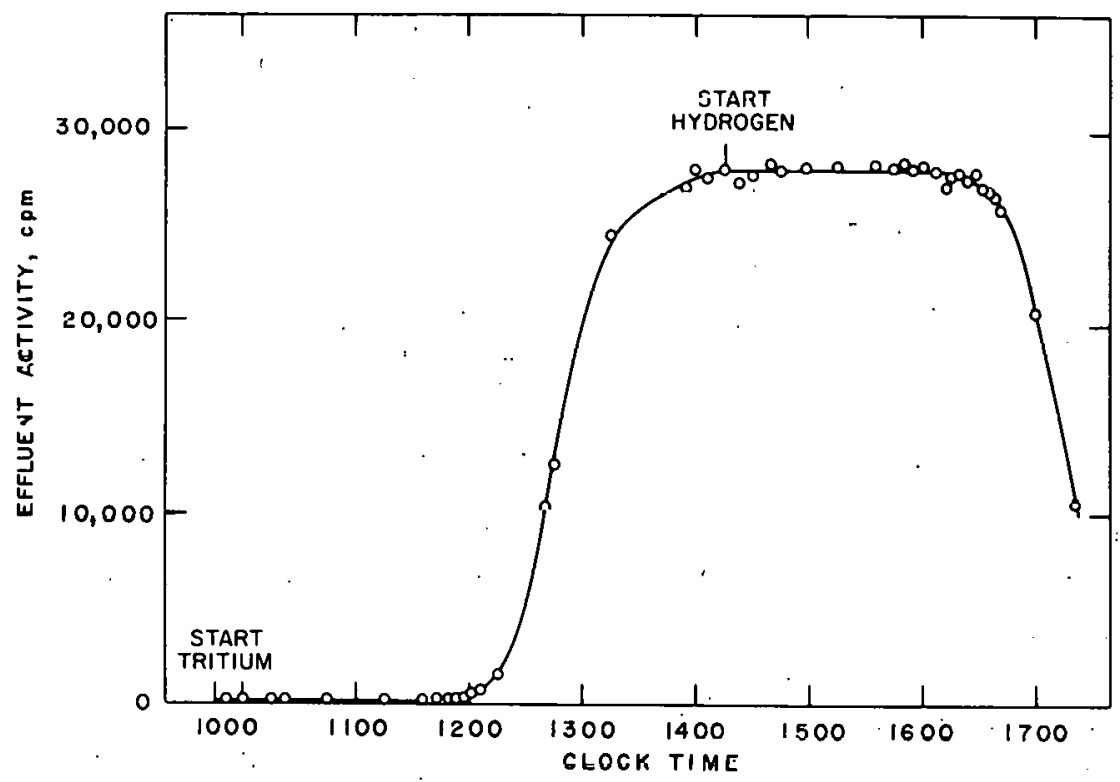

Figure 4. Hydrogen and tritium displacement on vanadium hydride, run No. 64. 
pure hydrogen. The former is measured by the amount of gas that passes through before any (or some arbitrary level of) activity appears in the effluent. The latter refers to the steepness of rise in effluent activity. For a curve such as that of Figure 4, it is convenient- to measure this by the time elapsing between the appearance of $10 \%$ of the saturation activity and the attainment of saturation. For the experiment shown, the $10 \%$ activity level appeared at $2.6 \mathrm{hr}\left(t_{0.1}\right)$ and saturation at $4.25 \mathrm{hr}\left(\mathrm{t}_{\text {sat }}\right)$, the difference ( $t_{\text {rise }}$ ) being $1.65 \mathrm{hr}$.

A few breakthrough experiments were conducted under different conditions. In some, the coarse vanadium powder was mixed with an approximately equal volume of Chromosorb. Thus, for run No. 23 the conditions were as follows: column dimensions, $4 \mathrm{ft} \times \frac{1}{4}-$ in.-0.d.; loading, $22.7 \mathrm{~g} \mathrm{~V}$ plus $10.3 \mathrm{~g}$ Chromosorb; temperature, $30^{\circ} \mathrm{C}$; pressure, $58 \mathrm{psia}$; flow rate, $17 \mathrm{cc} / \mathrm{min}$. A plot of the data yielded the following: $t_{0.1}=3.67 \mathrm{hr}, t_{\text {sat }}=9 \mathrm{hr}, \mathrm{t}_{\text {rise }}=$ $5.3 \mathrm{hr}$. The purified volume corresponding to $t_{0.1}$ was 3.7 1iters, somewhat less than the 4.7 liters of run No. 64. Since the amounts of vanadium in the two columns were the same, the inferior performance of No. 23 can probably be ascribed to the longer column lengths or lower flow rate, or both. These factors could have promoted longitudinal mixing to the detriment of efficiency. Such mixing is also suggested by the much longer $t_{\text {rise }}$ of run No. 23 . A more direct measure of the effect of column length alone is afforded by comparison of runs 23 and 18. These differed only in that, in run No. 18, only $17 \mathrm{~g} \mathrm{~V}$ was used (mixed with Chromosorb) and the column length was $3 \mathrm{ft}$ instead of 4 . I'he results were $\tau_{0.1}=2.5 \mathrm{hr}, L_{\text {sat }}=5.3 \mathrm{hr}$, ${ }_{\text {rise }}{ }^{-}$ $2.8 \mathrm{hr}$; volume corresponding to $t_{0.1}, 2.6$ liters. The comparison bears out, very roughly, the expectation that both the capacity of the column and $t_{\text {rise }}$ would be proportional to column length. The longer the travel time of a front, the more it will be widened by longitudinal diffusion.

\section{Band Experiments}

Intensive study of the effects of operating variables was not pursued with breakthrough runs because it was found that band experiments gave 
more information in less time. A typical experiment (run No. 33) is illustrated in Figures 2 and 3. The points in Figure 2. represent one-minute. counts on the flowing effluent gas; Figure 3 is a photograph of the stripchart record of the rate-meter, on the same gas. The conditions, which were quite similar to those of the breakthrough run No. 64 except for the presence of diluent, were as follows: column, $2 \mathrm{ft} \times \frac{1}{4}-\mathrm{in} .-0 . \mathrm{d}$.; loading, $14 \mathrm{~g} \mathrm{~V}$ of. about 200 mesh plus $2.4 \mathrm{~g}$ Chromosorb; temperature $30^{\circ} \mathrm{C}$; pressure, 35 psig at column inlet, 20 psig at outlet; flow rate, $17 \mathrm{cc} / \mathrm{min}$. After the column had come to equilibrium with flowing normal hydrogen, the influent stream was interrupted and replaced for $2 \frac{1}{2}$ min by an equal stream of tritium-traced hydrogen. The normal hydrogen supply was then restored, with the same flow conditions as before. As Figure 2 shows, the tritium activity appeared in the effluent about $3 \frac{1}{2} \mathrm{hr}$ (the retention time) 1ater. It had widened, from its original $2 \frac{1}{2} \mathrm{~min}$, into a bell-shaped band with a width, at the base, of about 138 min. (The base width, $t_{b}$, is defined as the distance, on the time axis, between the intercepts of tangents to the bell at the points of steepest slope. Drawing the tangents is admittedly a somewhat subjective operation.) It is convenient to define the effirienry nf a solumn in tarme of the time to peak maximum, $t_{\text {max }}$, and the bandwidth, which may be taken as $t_{b}$ or as the width at a specified height. Two measures of ten used are $t_{0.607}$ and $t_{n .368}$, the widths on the time axis of the band at the nrinate points that are respectively 0.607 and 0.368 of the maximum. The corresponding equations for the number of theoretical plates, $N$, are.

$$
\begin{aligned}
& \mathrm{N}_{1}=4\left(\mathrm{t}_{\max } / \mathrm{t}_{0.607}\right)^{2}, \\
& \mathrm{~N}_{2}=8\left(\mathrm{t}_{\max } / \mathrm{t}_{0.368}\right)^{2}, \\
& \mathrm{~N}_{3}=16\left(\mathrm{t}_{\max } / \mathrm{t}_{\mathrm{b}}\right)^{2},
\end{aligned}
$$

For a perfectly Gaussian curve all three give the same value. With a given set of experimental points, one or the other may prove easiest to apply. 
N-values may also be obtained from the area under. the curve, A, the value of the ordinate at the peak maximum, $h$, and $t_{\max }$. The equation is

$$
\mathrm{N}_{4}=2 \pi\left(h t_{\max } / \mathrm{A}\right)^{2}
$$

The quotient $\ell / N$, where $\ell$ is the effective length, becomes the "hetp" or height equivalent to a theoretical plate. The absolute values of $\mathrm{N}$ and hetp obtained in this work are not very precise, but the relationship between results of runs in which a variable is changed can be significant. The effects of changes are assessed below in terms of these somewhat arbitrary stage numbers or hetp values.

To return to run No. 33, Eqs. (1), (2), (3), and (4) gave $N$ values of $36,40,44$, and 38 respectively, averaging 39.5 ; hetp. was $1.56 \mathrm{~cm}$. When the run was repeated several times to test reproducibility, a continual slight deterioration was observed, breakthrough occurring a little sooner with each successive run. It was surmised that this was caused by gaseous impurities in the hydrogen, possibly water vapor, which could form oxide films on the hydride surface. Eventually, improvement was obtained by passing the hydrogen carrier gas over hot calcium just before use.

It was found that deteriorated columns could be restored to their original condition by subjecting them to two or three cycles of evacuation at $400^{\circ}$ and re-hydriding at room temperature. In an elution run (No. 38) after such a treatment, carried out on the same column that was used for. run No. 33 and under the same conditions, the $t_{\max }$ was $210 \mathrm{~min}$, compared with 218 for run No. 33, and the value of $N$ was the same within experimental uncertainty.

\section{Effect of Particle Size}

To test the effect of vanadium mesh size on efficiency, a column was charged with 320-mesh metal, mixed as before with an approximately equal volume of Chromosorb. Since the pressure drop through this material was greater than through the previous 200-mesh charge, the total amount of vanadium had to be reduced from $14.0 \mathrm{~g}$ to $9.6 \mathrm{~g}$. Otherwise, conditions were held constant. The results (run No. 41A) were $t_{\max }=147 \mathrm{~min}, t_{b}=130 \mathrm{~min}$, and 
$\mathrm{N}=20$. It is interesting that breakthrough came considerably sooner than before, while bandwidth remained the same. If $\mathrm{N}$ is corrected for the decreased amount of vanadium (assuming direct proportionality), the number obtained is 30 , vs. 45 with the coarser charge. The latter is evidently to be preferred.

A still coarser substrate was then tested, this time without added Chromosorb. The usual 2-ft coil was charged with vanadium of 10 to 20 mesh. Operating conditions were kept essential1y the same $\left(30^{\circ} \mathrm{C}, 16.5 \mathrm{cc} / \mathrm{min}\right.$ flow rate) except that now there was virtually no pressure drop across the column. Column pressure was 37 psia. An excellent run, No. 42, resulted: $t_{\max }^{\prime}=$ 394, $t_{b}=199 ; N=63$, hetp $=0.9 \mathrm{~cm}$. Reproducibility was tested by carrying out four more runs, Nos. 43A, B, C, and D, under approximately the same conditions. The results were as follows:

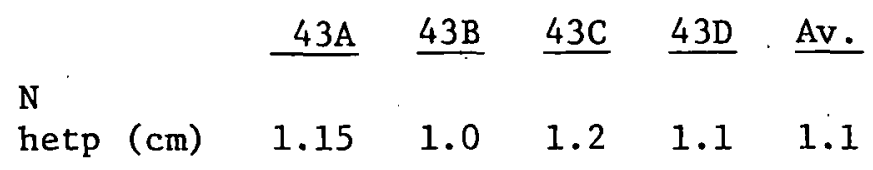

These numbers, it should be noted, were obtained from the strip-chart reçord of the rate-meter and are not directly comparable with the $\mathrm{N}=63$ of run No. 42, which was obtained from one-minute counts. For some reason, the ratemeter trace (which was less precise) always indicated a worse performance. For relative results, however, it was adequate. (One-minute counts were not always taken.) It can be seen that there was a slight fall-off in efficiency but that this was not progressive.

4. Effect of Flow Rate

Several serles of runs were carried out with no changes from No. 43 except in flow rate, which was taken as high as $115 \mathrm{cc} / \mathrm{min}$. The results are presented in Table 1 and Figure 5. Thc number of stages decreases with increasing flow rate in a roughly linear way.

5. Effect of Temperature

An inerease in tempcrature should hasten the approach to gas-solld equilibrium and therefore increase the number of stages. This was confirmed 


\section{Table 1}

Effect of Flow Rate on Number of Theoretical Stages, N, in a Vanadium Column at $30^{\circ} \mathrm{C}$

\begin{tabular}{|c|c|c|c|c|}
\hline F1ow & rate, $c c / m i n$ & $\therefore$ Run No. & $\mathbf{N}$ & $N$ (group av.) \\
\hline \multirow{4}{*}{\multicolumn{2}{|c|}{16.5}} & $43 A$ & 48 & \multirow{4}{*}{50} \\
\hline & & B & 56 & \\
\hline & & C & 46 & \\
\hline & & .D & 50 & \\
\hline \multirow{3}{*}{\multicolumn{2}{|c|}{32.5}} & $44 \mathrm{~A}$ & 47 & \multirow{3}{*}{46} \\
\hline & & B & .46 & \\
\hline & & $C$ & 46 & \\
\hline \multirow{3}{*}{\multicolumn{2}{|c|}{64}} & $45 \mathrm{~A}$ & 29 & \multirow{3}{*}{27} \\
\hline & & B & 25 & \\
\hline & & $\mathrm{C}$ & 26 & \\
\hline \multirow{3}{*}{. } & 115 & $51 \mathrm{~A}$ & 15 & \multirow{3}{*}{14} \\
\hline & & B & 14 & \\
\hline & & C & 14 & \\
\hline
\end{tabular}

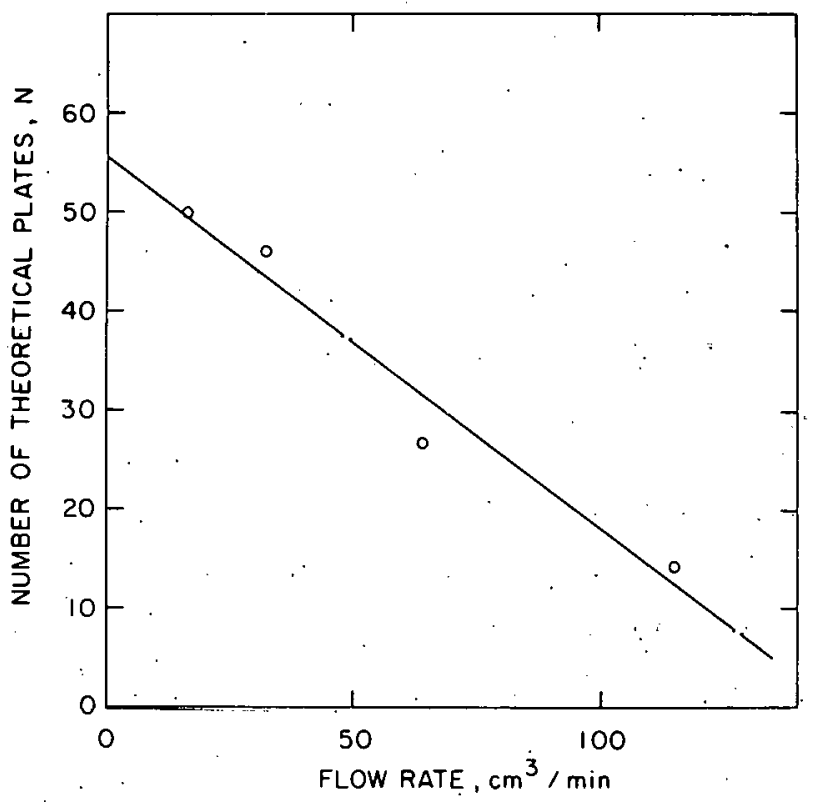

Figure 5. Effect of flow rate on vH column performance at $30^{\circ} \mathrm{C}$. 
in a qualitative way by a few runs in which only the temperature was varied. The results of runs $44 \mathrm{~A}, \mathrm{~B}$, and $\mathrm{C}$, at $30^{\circ}$ (Table 1 ) may be compared with those of runs $46 \mathrm{~A}, \mathrm{~B}$, and $\mathrm{C}$, at $40^{\circ}$. In the latter series, $\mathrm{N}$ values of 62 , 43, and 45 were obtained. These average 50 , compared with 46 for the $30^{\circ}$ runs, but the real difference may be greater, if the high value in the first $40^{\circ}$ run is given more weight on the assumption that the column deteriorated later. A better measure of the temperature effect was later obtained on a different column run at $70^{\circ}$ (run No. 67) and then at $30^{\circ}$ (run No. 68) on the same day. The respective numbers of stages were 101 and 32 , as calculated from curves constructed from one-minute counts; or 36 and 21 , from the stripchart data. Whichever comparison is accepted, a definite improvement is seen on going to $70^{\circ}$.

\section{Effect of Solid Composition}

Several runs were carried out at $0^{\circ} \mathrm{C}$ in order to extend the range of temperature comparisons. Performance was poor, about 10 stages being found under conditions that gave 25 to 30 at $30^{\circ}$. The band became asymetrical, the trailing edge being drawn out. These effects probably are not due to temperature alone but are related to the partial conversion of the substrate to $\mathrm{VH}_{2}$. The decomposition pressure of this phase is only $1.3 \mathrm{~atm}$ at $0^{\circ}$ and it was slightly exceeded in the $0^{\circ}$ runs.

To see how $\mathrm{VH}_{2}$ hehaved at a higher trmperature, we carried uul a $30^{\circ}$ run at 145 psia, a pressure at. which $\mathrm{VH}_{2}$ is the stable phase. Flow rate was $32 \mathrm{cc} / \mathrm{min}$. Again performance was poor: the emerging band was wide and asymmetrical, as Figure 6 shows, and the $\mathrm{N}$ value (if the calculation has any meaning under the circumstances) was only 4.

7. Best Runs

The results of the two best vanadium runs are recorded here to facilitate engineering calculations and as a starting point for possible future resumption of research. The same column was used for both: a coil of $\frac{1}{4}$-in.-o.d. stainless steel tubing, filled for $61 \mathrm{~cm}$ of j.ts length with commercial grade vanadium of 10 to 20 mesh. The flow rate in each case was $35 \mathrm{cc} / \mathrm{min}$ and the pressure, $36.4 \mathrm{psia}$. Only the temperatures differed, 
being $70^{\circ}$ in run No. 67 and $25^{\circ}$ in run No. 78. The results, as calculated three ways, were as follows:

$\begin{array}{lll} & \text { Run } 78,25^{\circ} & \text { Run } 67,70^{\circ} \\ \mathrm{N}_{1} & 54 & 75 \\ \mathrm{~N}_{2} & 52 & 78 \\ \mathrm{~N}_{3} & 78 & 101 \\ \mathrm{~N}_{\text {av }} & 61 & 85\end{array}$

Figures 7 and 8 show the elution curves.

\section{B. Other Hydrides}

1. $\mathrm{LaNi}_{5}$

The intermetallic compound $\mathrm{LaNi}_{5}$ forms a hydride of the approximate composition $\mathrm{LaNi}_{5} \mathrm{H}_{7}$, which has an isotope effect in the same direction as that of vanadium but somewhat smaller. ${ }^{1}$ To study its chromatographic behavior, a series of band-passage experiments was carried out under the same conditions that were used for vanadium. The alloy was prepared by arcmelting the pure metals together. The ingot was then ground into a coarse powder. About $20 \mathrm{~g}$ alloy was mixed with $5.5 \mathrm{cc}$ Chromosorb, charged into a 60-cm length of $\frac{1}{4}-i n .-o . d$. stainless steel tubing, and subjected to several cycles of hydriding and dehydriding. Finally, with the column in its hydride form, tritium retention times and bandwidths were obtained and used to calculate a theoretical plate number as before. The effects of changes in temperature, pressure, and flow rate were ascertained. Results of the series of runs are presented in Table 2. The first three columns give the values of the operating variables; the next two give the equilibrium dissociation pressure of the hydride at the operating temperature and the retention time, $t_{\text {max }}$; and the last column gives the number of theoretical plates found by using Eq. (3).

Certain conclusions are evident. When the operating pressure was below the equilibrium dissociation pressure, as in the first two runs, breakthrough was immediate as indicated by a $<1$ value for $N$. If the pressure 


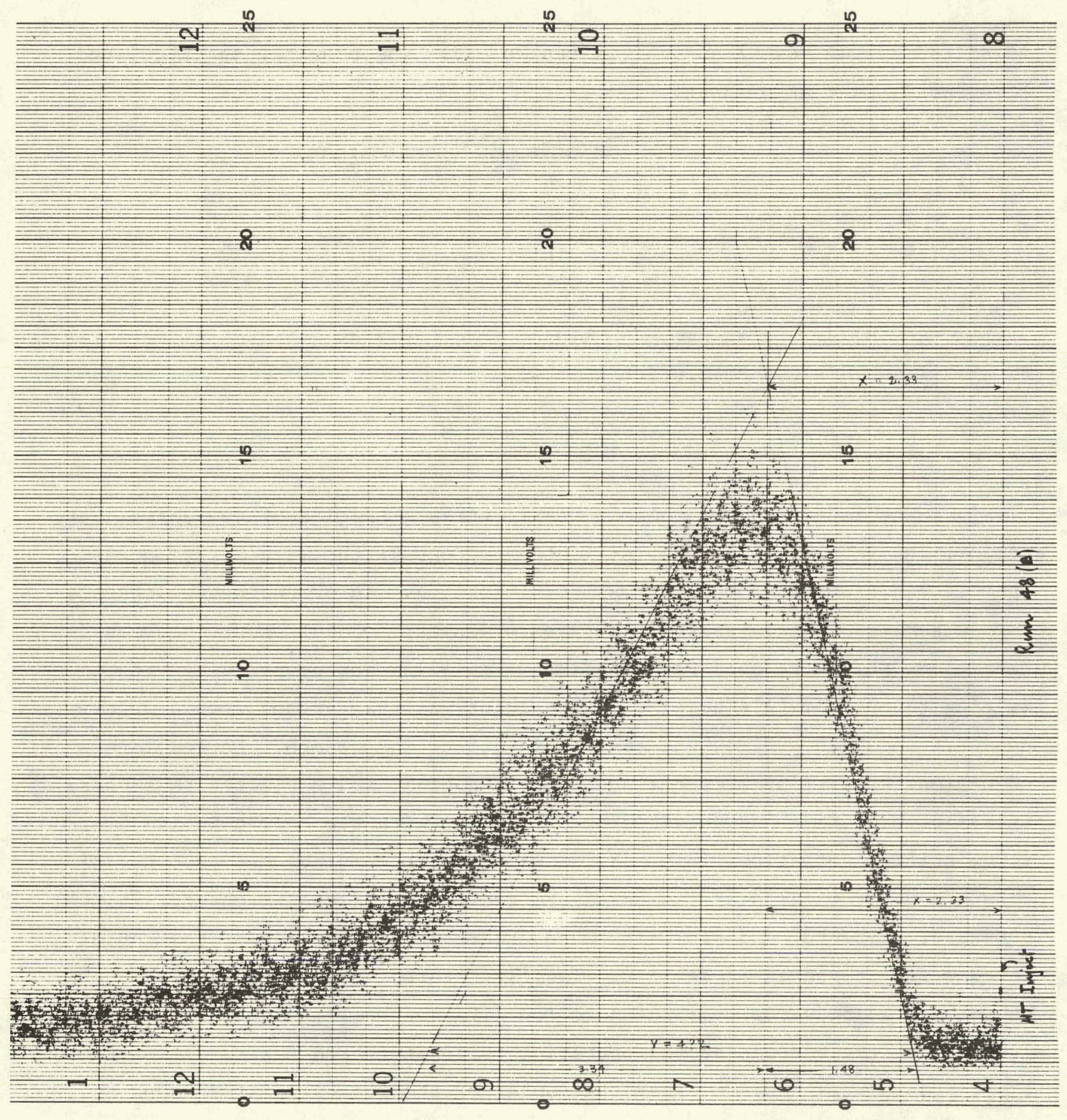

Figure 6. Elution of tritium from vanadium hydride, strip-chart record of run No. $48 \mathrm{~B}$. 


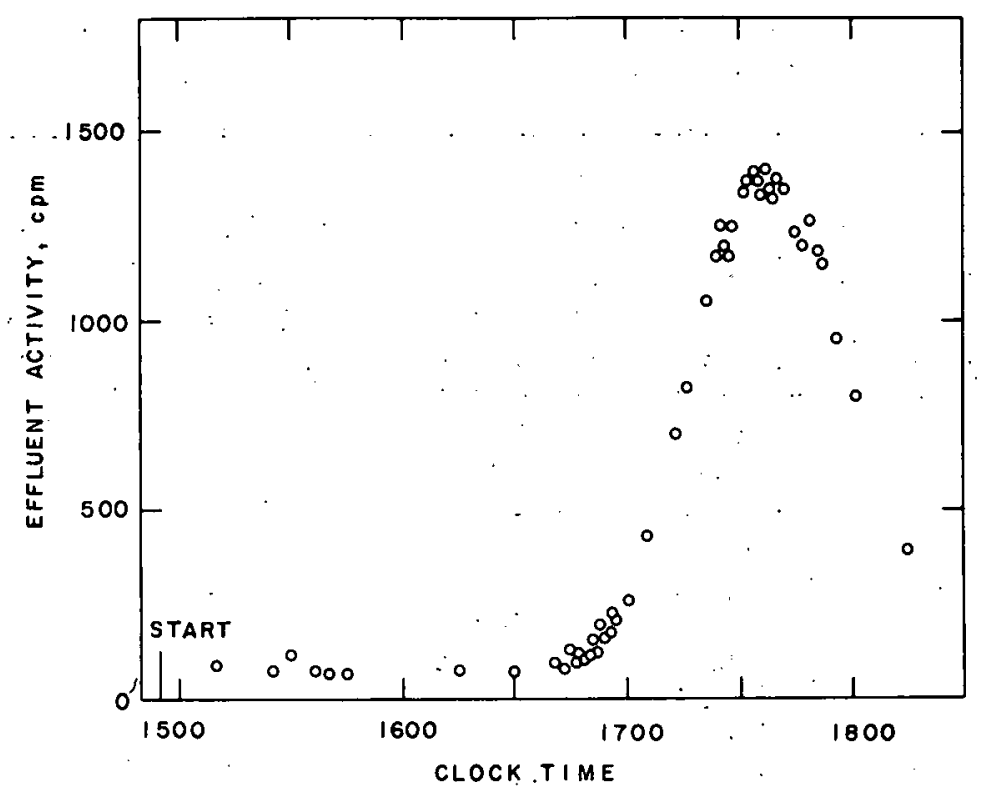

Figure 7. Elution of tritium from vanadium hydride at $70^{\circ} \mathrm{C}$, run No. 67 .

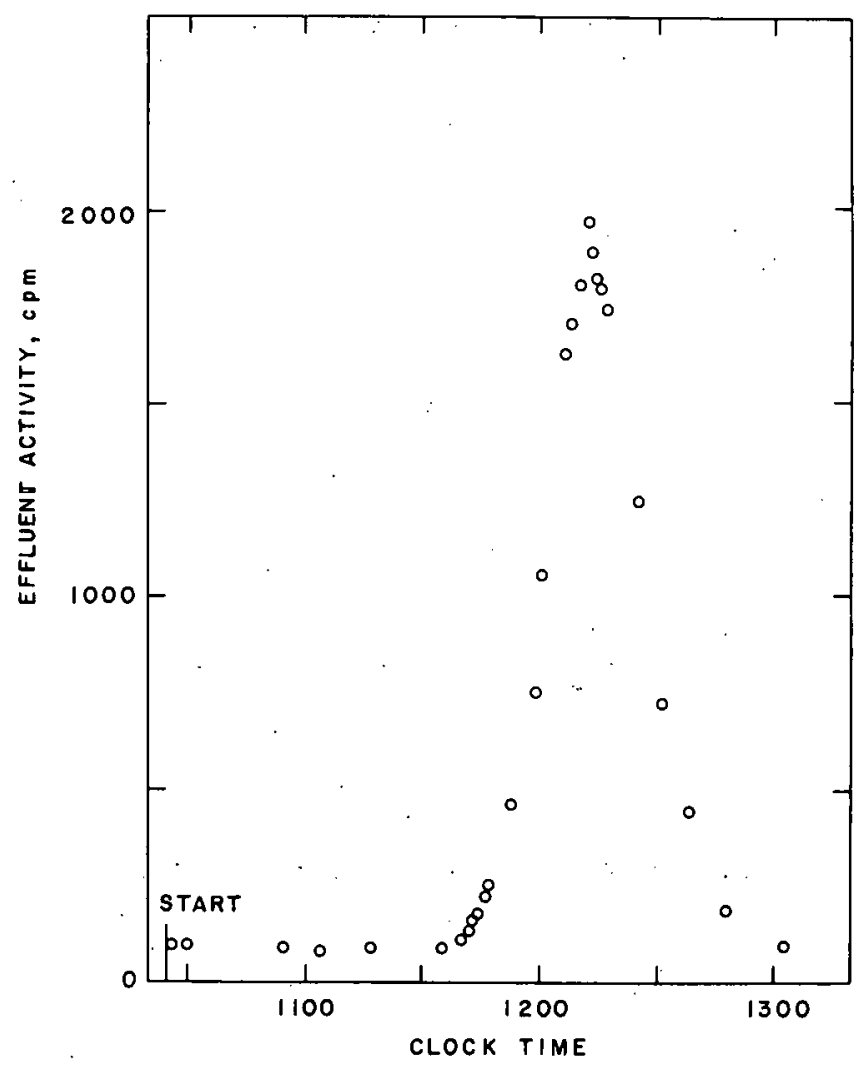

Figure 8. Elution of tritium from vanadium hydride at $25^{\circ} \mathrm{C}$, run No. 78 . 
Table 2

Chromatographic Performance of Lanthanum-Nickel Hydride

\begin{tabular}{rccccc}
\hline $\begin{array}{c}\text { Temp., } \\
{ }^{\circ} \mathrm{C}\end{array}$ & $\begin{array}{c}\text { Operating } \\
\text { press., atm }\end{array}$ & $\begin{array}{c}\text { Flow rate, } \\
\text { cc/min }\end{array}$ & $\begin{array}{c}\text { Equilib. } \\
\text { press., atm }{ }^{13}\end{array}$ & $\begin{array}{c}\text { Retent. time, } \\
\text { tmax }_{\text {min }} \text {, min }\end{array}$ & $\begin{array}{c}\text { No. of } \\
\text { theor. plates }\end{array}$ \\
\hline 60 & 1 & 16.5 & 4.9 & $<1$ & $<1$ \\
30 & 1 & 16.5 & 1.57 & $<1$ & $<1$ \\
0 & 1 & 16.5 & 0.4 & 52 & 14.8 \\
0 & 1 & 16.5 & 0.4 & 160 & 25.2 \\
-20 & 1 & 16.5 & 0.135 & 298 & 37.6 \\
-20 & 1 & 16.5 & 0.135 & 298 & 35.0 \\
-78 & 1 & 16.5 & 0.00145 & 426 & 18.1 \\
-78 & 1 & 31.5 & 0.00145 & 174 & 8.1 \\
30 & 3 & 16.5 & 1.57. & 30 & 29.7 \\
30 & 4 & 16.5 & 1.57 & 229 & 41.6 \\
30 & 11 & 16.5 & 1.57 & 258 & 42.1 \\
30 & 20 & 16.5 & 1.57 & 258 & 47.3 \\
30 & 20 & 16.5 & 1.57 & 249 & 46.0 \\
\hline
\end{tabular}

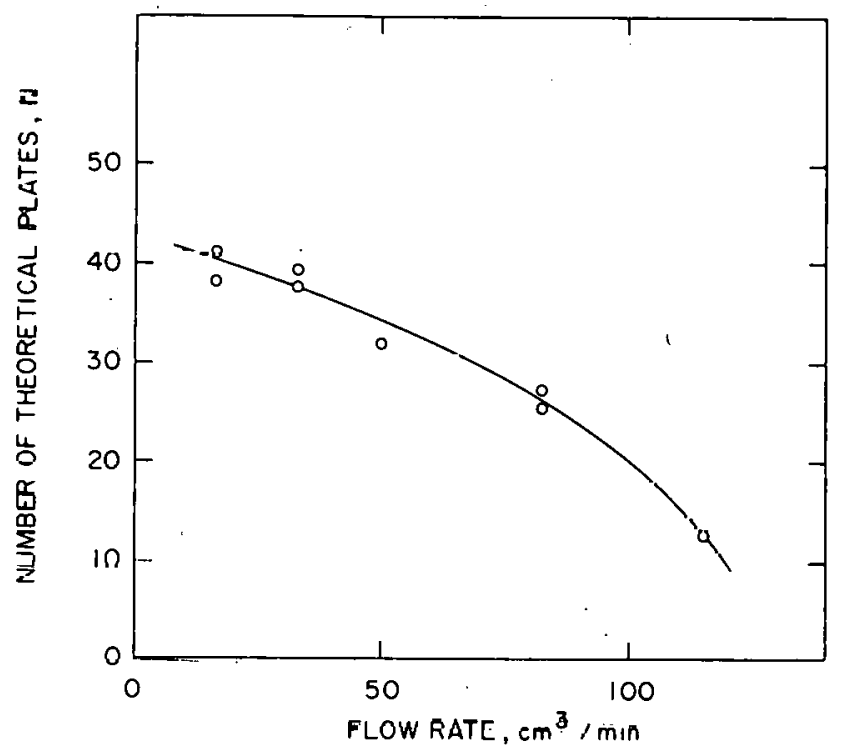

Figure 9. Effect of flow rate on performance of Mischmetall-nickel hydride column at $30^{\circ} \mathrm{C}$. 
condition was satisfied, however, chromatographic behavior was observed over the temperature range $-78^{\circ}$ to $+30^{\circ} \mathrm{C}$. At $-20^{\circ}$, column behavior was better than at $-78^{\circ}$, as expected. The anomalous poor behavior at $0^{\circ} \mathrm{C}$ may possibly be due to a loss of hydrogen from the solid, which, because of the pressure-composition hysteresis phenomenon, would probably not be made up from the ambient hydrogen at $1 \mathrm{~atm}$.

The $30^{\circ} \mathrm{C}$ runs, whien conducted at an adequate pressure, gave good and consistent results. The average $\mathrm{N}$ of the last four runs was 44 and the hetp, $1.4 \mathrm{~cm}$. Pressure seemed to make no difference in the range between 4 and $20 \mathrm{~atm}$, but a possibly significant fall-off was seen at 3 a.tm.

Since these results were obtained on the first column tried, and many variations on the preparation of the substrate are possible, it is probable that additional effort would result in columns at least as good as those with vanadium.

\section{2. $\mathrm{MmNi}_{5}$}

The lanthanum in $\mathrm{LaNi}_{5}$ can be replaced by other rare earth metals or by a mixture of them. One such mixture is the commercial alloy Mischmetall (Mm). Since alloys of nickel with Mischmetall, $\mathrm{Mmi}_{5}$, had been made in our laboratory for another purpose, we decided to test one as a chromatographic substrate. In the alloy chosen, the rare earth portion had the composition (in wt \%): $\mathrm{Ce}, 50 ; \mathrm{La}, 24 ; \mathrm{Nd}, 14 ; \mathrm{Pr}, 4$; other rare earth metals, 2. An alloy of similar composition had been found ${ }^{1}$ to have a tritium-protium separation factor of 1.29 at $0^{\circ} \mathrm{C}$.

A column was made up and operated by the previously described procedures. In this case, the temperature and pressure were kept constant throughout all runs, at $30^{\circ} \mathrm{C}$ and 25 atm. Since the dissociation pressure of the hydrided alloy is known ${ }^{10}$ to be 21 atm at $30^{\circ}$, there should have been no loss of hydrogen from the solid. Eight runs were made, in which the flow rate was varied from 16.5 to $115.5 \mathrm{cc} / \mathrm{min}$. The results, given in Figure 9, show that performance is similar to that of $\mathrm{LaNi}_{5}$. 


\section{3. $\mathrm{Mg}_{2} \mathrm{Ni}$}

The alloy $\mathrm{Mg}_{2} \mathrm{Ni}$ forms a hydride ${ }^{11} \mathrm{Mg}_{2} \mathrm{NiH}_{4}$ which has a tritiumprotium separation factor of 0.45 in the range $250^{\circ}$ to $325^{\circ}$, i.e., the isotope effect is in the opposite direction to that of vanadium and $\mathrm{LaNi}_{5}$. This means that in principle the retention time of a tritium band will be shorter on a $\mathrm{Mg}_{2} \mathrm{NiH}_{4}$ column; but the effect will not be large. Our bandpassage experiments did not lend themselves to quantitative determination of separation factors; their value lay in the kinetic information they yielded.

A column was charged with $\mathrm{Mg}_{2} \mathrm{Ni}$ and, after the usual activation and final hydriding, a series of runs was carried out as before. The operating conditions and resules are presented in Table 3 . Inspectiun of the data shows that temperature is very important in this series. At $30^{\circ}$ and $60^{\circ} \mathrm{C}$, immediate breakthrough occurred; even at $300^{\circ} \mathrm{C}$ the retention time was very short and the number of stages was small. The chromatographic behavior continued to improve with temperature up to $375^{\circ} \mathrm{C}$, the highest temperature that could be reached without loss of hydrogen at the maximum convenient operating pressure of $20 \mathrm{~atm}$. The relation is roughly linear and can be approximated by the equation $\mathrm{N}=0.28(\mathrm{~T}-274)$ where $\mathrm{T}$ ls ln $^{\circ} \mathrm{C}$. The relationship is plotted in Figure 10. Efficiency was not very sensitive to flow rate up to $33 \mathrm{cc} / \mathrm{min}$.

\section{Zirconium}

For comparison with the previous materials, it was desirable to study the chromatographic behavior of the very stable hydride $\mathrm{ZrH}_{2}$. The same procedure was used, 1.e., Land-pasange ruus, carricd out from $25^{\circ}$ to $600^{\circ} \mathrm{C}$. Table 4 and Figure 11 present the results. With this system, the passage of tritium was delayed only above about $450^{\circ} \mathrm{C}$. From $500^{\circ} \mathrm{C}$ up, the dependence of stage number un tempernture was apprnximately linear, with a slope, dN/dT, of 0.18 , somewhat smaller than the value of 0.28 found for magnesium nicke1 hydride. 
Table 3

Chromatographic Performance of Magnesium-Nickel Hydride (Estimated column charge: $13 \mathrm{~g}$ )

\begin{tabular}{rrrrrr}
\hline $\begin{array}{c}\text { Temp., } \\
{ }^{\circ} \mathrm{C}\end{array}$ & $\begin{array}{c}\text { Operating } \\
\text { press., atm }\end{array}$ & $\begin{array}{c}\text { Flow rate, } \\
\text { cc/min }\end{array}$ & $\begin{array}{c}\text { Equilib. } \\
\text { press., atm } 11\end{array}$ & $\begin{array}{c}\text { Retent, time, } \\
t_{\text {max }} \text {, min }\end{array}$ & $\begin{array}{c}\text { No. of } \\
\text { theor. plates }\end{array}$ \\
\hline 36 & 2 & 16.5 & $3.3 \times 10^{-5}$ & $<1$ & $<1$ \\
60 & 2 & 16.5 & $2.0 \times 10^{-4}$ & $<1$ & $<1$ \\
250 & 3 & 16.5 & 1.09 & 48 & 8.0 \\
300 & 6 & 16.5 & 3.35 & 122 & 7.4 \\
325 & 10 & 16.5 & 5.89 & 120 & 13.7 \\
325 & 15 & 16.5 & 5.89 & 80 & 11.6 \\
325 & 15 & 16.5 & 5.89 & 88 & 14.8 \\
350 & 15 & 16.5 & 9.91 & 113 & 21.2 \\
375 & 15 & 16.5 & 16.0 & 88 & 28.7 \\
375 & 20 & 16.5 & 16.0 & 112 & 25.9 \\
375 & 20 & 16.5 & 16.0 & 107 & 27.8 \\
375 & 20 & 8.5 & 16.0 & 226 & 20.5 \\
375 & 20 & 33.0 & 16.0 & 48 & 24.2 \\
375 & 20 & 16.5 & 16.0 & 100 & 28.8 \\
\hline
\end{tabular}

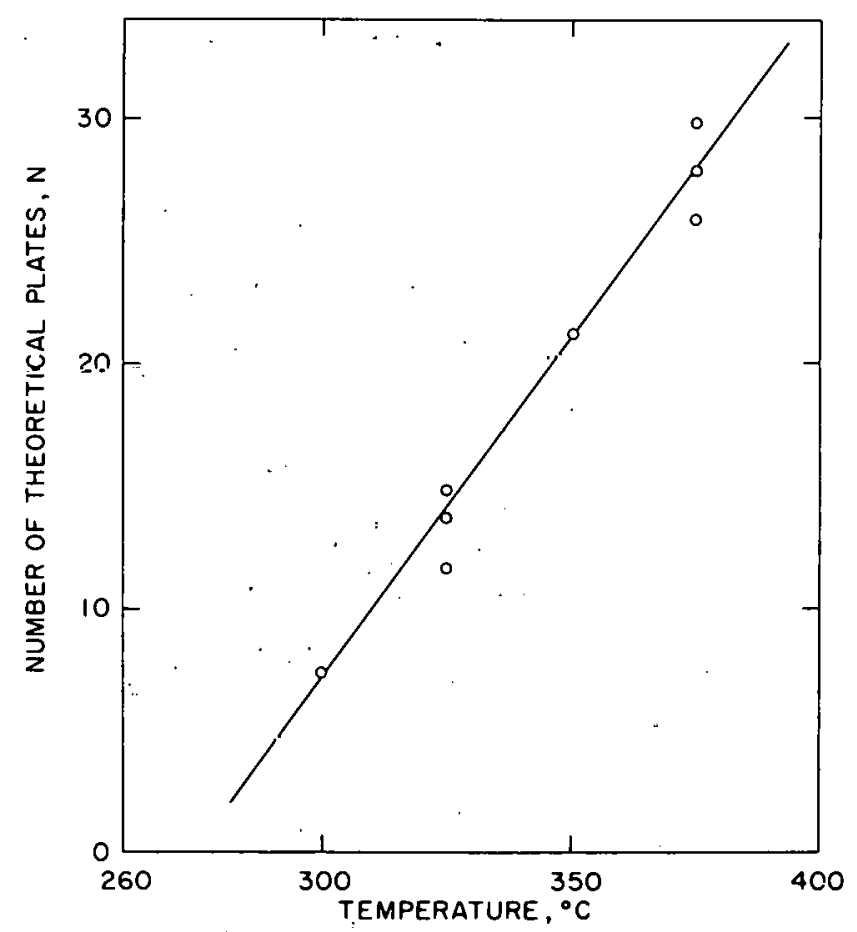

Figure 10. Effect of temperature on perfurmance of $\mathrm{Mg}_{2} \mathrm{Ni}$ hydride column. 
Table 4

Chromatographic Performance of Zirconium Hydride

(Column loading: $30.90 \mathrm{~g}$ metal, undiluted, in $24 \mathrm{in}$. of $\frac{1}{4}-\mathrm{in.}-0 . \mathrm{d}$. tube)

\begin{tabular}{cccccc}
\hline $\begin{array}{c}\text { Temp., } \\
{ }^{\circ} \mathrm{C}\end{array}$ & $\begin{array}{c}\text { Operating } \\
\text { press., atm }\end{array}$ & $\begin{array}{c}\text { Flow rate, } \\
\text { cc/min }\end{array}$ & $\begin{array}{c}\text { Equilib. } \\
\text { press., Torr }\end{array}$ & $\begin{array}{c}\text { Retent. time, } \\
\text { tmax } \\
\text { min }\end{array}$ & $\begin{array}{c}\text { No. of } \\
\text { theor. plates }\end{array}$ \\
\hline 25 & 1 & 16.5 & $<10^{-4}$ & $<1$ & $<1$ \\
300 & 1 & 16.5 & $<10^{-4}$ & $<1$ & $<1$ \\
350 & 1 & 16.5 & $<5 \times 10^{-4}$ & 3 & $<1$ \\
450 & 1 & 16.5 & 0.002 & 252 & 4.4 \\
500 & 1 & 16.5 & 0.01 & 354 & 8.7 \\
530 & 1 & 16.5 & 01.118 & 400 & 18.6 \\
600 & 1 & 16.5 & 0.6 & 418 & 27.0 \\
600 & 1 & 82.5 & 0.6 & 112 & 17.3 \\
\hline
\end{tabular}

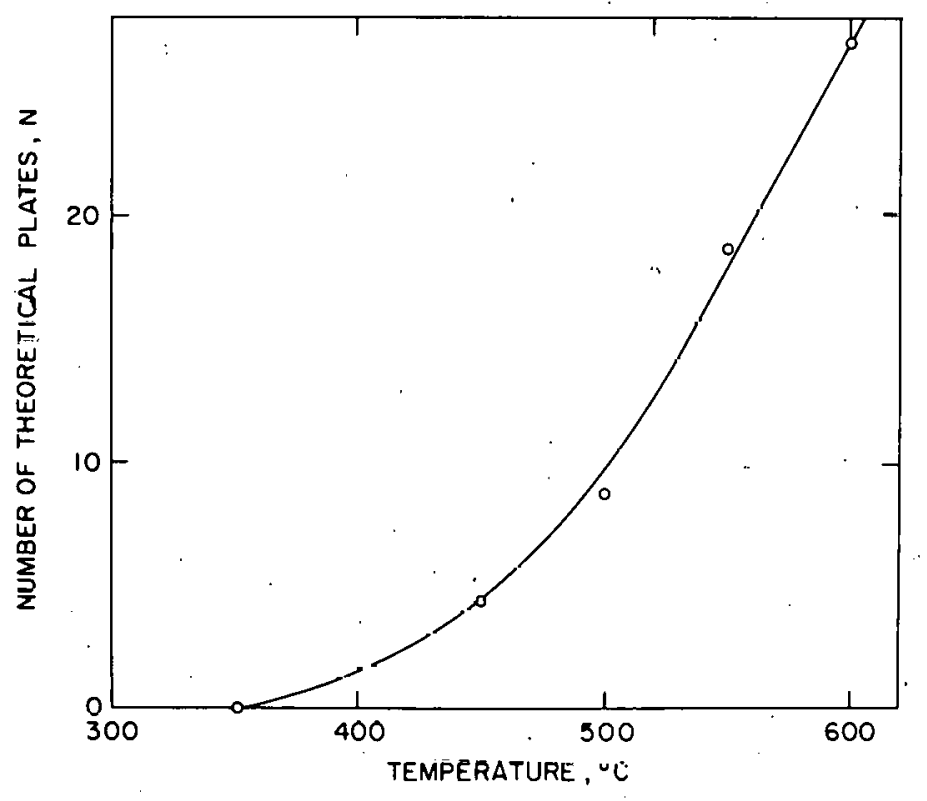

Figure 11. Effect of temperature on performance of zirconium hydride column. 


\section{Comparison of Systems}

The data of the preceding four sections suggest a relationship between the onset of chromatographic behavior and the temperature at which the dissociation pressure of the hydride becomes appreciable. This is in accord with the expectation that tritium retention will not occur unless there is rapid exchange at the surface between hydrogen in the gas phase and in the solid. A necessary and perhaps sufficient condition for rapid exchange would be at least a moderate dissociation pressure. Such a pressure implies dynamic equilibrium at the gas-solid interface.

A closer look at the data shows some inconsistencies. With $\mathrm{Mg}_{2} \mathrm{NiH}_{\mathrm{x}}$, performance remained poor even at a temperature $\left(300^{\circ}\right)$ where the dissociation pressure is $>3 \mathrm{~atm}$, whereas, with $\mathrm{Zr}$, fair performance was obtained when the $\mathrm{ZrH}_{2}$ pressure was $<1$ Torr, at $600^{\circ} \mathrm{C}$. An explanation may lie in differences between sticking coefficients. The rate of surface exchange is limited by the rate at which gas molecules become incorporated in the solid. At equilibrium this rate is proportional to the dissociation pressure and to the sticking coefficient. It is possible, therefore, that the slow rate of $\mathrm{Mg}_{2} \mathrm{NiH}_{\mathrm{x}}$ is due to a small value of the latter. Another possibility is that in some cases the exchange rate is limited not by the surface reaction but by subsurface diffusion. The compound $\mathrm{Mg}_{2} \mathrm{NiH}_{x}$ is saltlike, whereas the other hydrides tested are metallic; a difference in diffusion coefficients is likely.

\section{Dua1-Temperature Experiments}

As mentioned in the Introduction, a simple isotope separation process can be based on a hydride that has a temperature-dependent isotope effect. Vanadium has such a property, ${ }^{1}$ and, since its chromatographic behavior had been demonstrated, we decided to test the unit process that might be made the basis of a separation plant. The method was to equilibrate a column of vanadium hydride like those described above with flowing tritium-traced hydrogen at a low temperature. Then, as quickly as possible, the temperature was raised. The separation factor being thus decreased, the gas stream should pick up tritium from the solid. A "front" of higher tritium 
concentration should form, move slowly through the column, and eventually break through, to be detected by the downstream proportional counter. When the temperature was then lowered to its original value, the incoming gas should begin to give up tritium to the solid, and a front of the opposite sense form. The more efficient the column, the greater the difference in the two effluent tritium concentrations and the greater the volume passed between breakthroughs.

The ideal ratio of the tritium concentrations in the high and low temperature effluents can be shown to be equal to the square of the ratio of the two separation factors. Let the tritium-hydrogen ratios be denoted by $t$, with subscripts as follows: $g$, gas in column in equilibrium with solid hydride; s, solid hydrtde; 1, at lower temperature; 2, at highcr temperature; 0 , in the incoming gas stream; $e$, in the effluent gas stream. The separation factors, $\alpha$, are then defined at the two temperatures as $\alpha_{1}=t_{s, 1} / t_{g, 1}$ and $\alpha_{2}=t_{s, 2} / t_{g, 2}$. Consider the case of a column equilibrated throughout with gas of composition $t_{0}$ at temperature 1 . For the solid, $t_{s, 1}=\alpha_{1} t_{0}$. When the temperature is raised, the gas in the column and in the early stages of effluent acquires the composition $t_{g, 2}=t_{s, 1} / \alpha_{2}=t_{0} \alpha_{1} / \alpha_{2}$, since the amount of hydrogen in the gas phase is negligible compared with that in the snlid, The continued influx of gas at $t_{0}$ will eventually convert all the solid to a composition $t_{s, 2}=\alpha_{2} t_{0}$, and the effluent concentration w1.1. be the samc ac the incoming. Now let the temperature be lowered again. The concentration of the column gas, and the effluent, becomes $t_{g, 1}=\alpha_{2} t_{0} / \alpha_{1}$. The ratio of the effluent concentrations immediately after the temperature changes is Llieretore

$$
t_{g, 2} / t_{g, 1}=\left(\alpha_{1} / \alpha_{2}\right)^{2}
$$

To see whether actual systems performed as predicted, a series of runs was carried out iu which tritium-trared hydrogen was fed to vanadium columns while they were cycled between $0^{\circ}$ and $70^{\circ} \mathrm{C}$. In an illustrative run (No. 82 ), of which a curve taken from a recorder trace is shown in Figure 12, the conditions were as follows: column, $2 \mathrm{ft} \times \frac{1}{4}-\mathrm{in} .-0 . d$. stainless steel tube; 


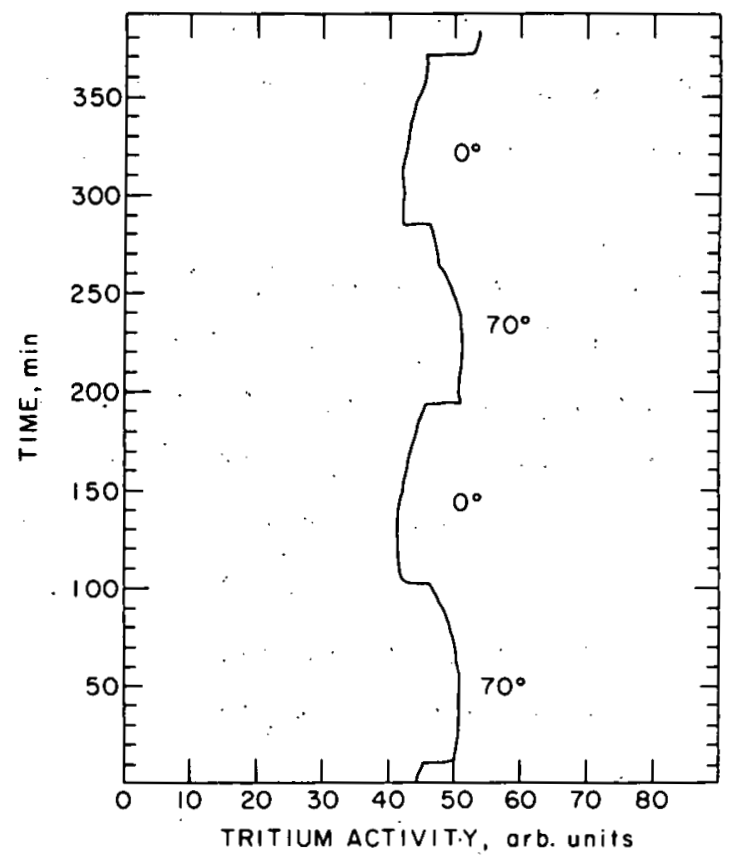

Figure 12. Enrichment and depletion of tritium in dual-temperature process, on vanadium hydride column.

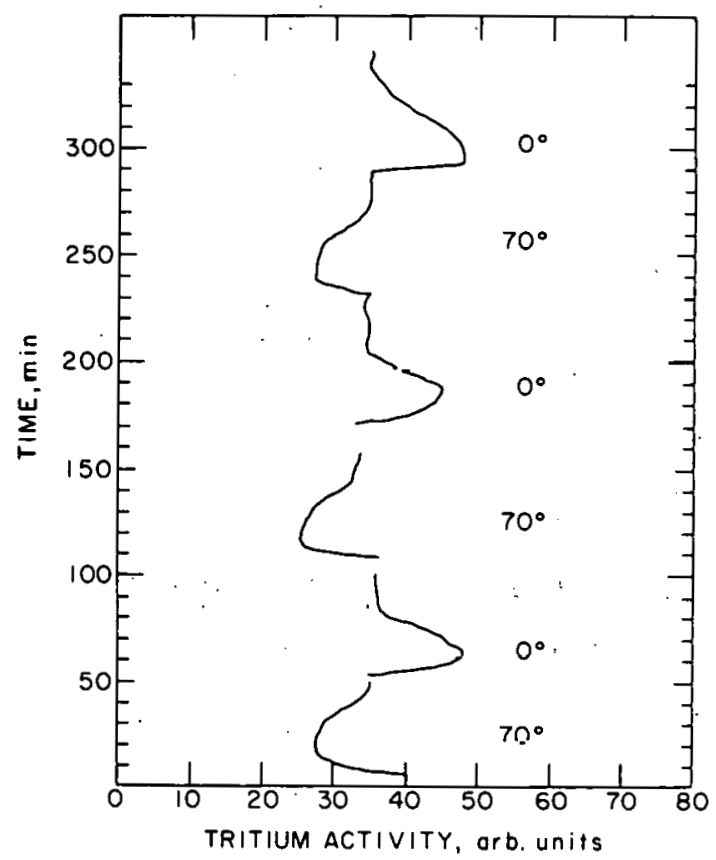

Figure 13. Depletion and enrichment of tritium in dual-temperature process, on palladium hydride column. 
charge, $22.965 \mathrm{~g}$ commercial vanadium, 10 to 20 mesh; gas flow rate, 34.5 cc/min; pressure, 17.5 psia. Each half of the two-temperature cycle lasted $1 \frac{1}{2} \mathrm{hr}$. At the end of each half-cycle the column was valved off and one constant-temperature bath was replaced by another. One hour was then allowed to elapse for equilibration before flow was resumed at the new temperature.

Figure 12 shows that appreciable isotope separation did indeed occur. For instance, compare the maximum activity value in the $70^{\circ}$ half of cycle 1 , about 51, with the minimum in the subsequent $0^{\circ}$ half-cycle, about 41.5 . - If these are corrected for a background reading of about 2 (not shown), the resulting ratio, $49 / 39.5=1.24$, provides a tentative value for $\left(\alpha_{0^{\circ}} / \alpha_{70^{\circ}}\right)^{2}$.

For practical purposes, it is not the maxima but the average values of the effluent concentraclous in the two halt-sycles lhat arc of interest. The activity vs, time curves were usually far from level, of ten with even more curvature than Figure 12 shows. A possible measure of column merit is the area, A, between a half-cycle curve and a reference line corresponding to the activity of the incoming gas. In practice, this line is drawn in such a way that the areas for the two half-cycles are equal. and opposite, as nearly as possible, for reasons of mass balance. Instead of a numerical value of $A$, it is convenient to use its ratio, $\vec{R}$, to the arta betwcen the reference line and the time axis, both being corrected for background; this gives a fractional enrichment or depletion. For run No. 82 , some values uf $R$ aro 28 follows:

\begin{tabular}{|c|c|c|c|c|c|}
\hline cycle 1: & $\begin{array}{r}0^{\circ} \\
70^{\circ}\end{array}$ & $\begin{array}{l}0.075 \\
0.080\end{array}$ & cycle 4: & $\begin{array}{r}0^{\circ} \\
70^{\circ}\end{array}$ & $\begin{array}{l}0.082 \\
0.076\end{array}$ \\
\hline rycle 2: & $\begin{array}{r}0^{\circ} \\
70^{\circ}\end{array}$ & $\begin{array}{l}0.080 \\
0.081\end{array}$ & cycle 5: & $\begin{array}{r}0^{\circ} \\
70^{\circ}\end{array}$ & $\begin{array}{l}0.064 \\
0.054\end{array}$ \\
\hline cycle 3: & $\begin{array}{r}0^{\circ} \\
70^{\circ}\end{array}$ & $\begin{array}{l}0.081 \\
0.085\end{array}$ & & & \\
\hline
\end{tabular}

That is to say, the $70^{\circ}$ effluent averaged about $8 \%$ richer in tritium than the incoming hydrogen, and the $0^{\circ}$ effluent was depleted by an cqual ammint. For any particular pair of half-cycles the material balance was often defective, but over the whole series it was fairly exact. 
These results are typical of a large number of runs, if allowance is made for a good deal of scatter. It. proved very difficult to reproduce any experiment exactly, and the effects of minor changes in the variables could not be determined because of random variations. Some runs gave less favorable results than the one illustrated; a few showed much better performance. The general trend was such that we believe a result as good as that of run No. 82 could be readily achieved in a repetition of this work.

One complication worth mentioning was the tendency for performance to deteriorate during the course of a series. This may have been due to impurities in the hydrogen, although stringent precautions were taken. Another problem may have been caused by our practice of adhering to uniform time cycles. This sometimes resulted in changing the temperature before a column had been completely converted to the current-temperature equilibrium condition; such a situation can result in a subsequent concentration vs. time curve that is difficult to analyze. Finally, it is probable that in the low temperature runs some $\mathrm{VH}_{2}$ formed, since pressures of 50 to 70 psia were observed when a column was valved off and heated to $70^{\circ} \mathrm{C}$. Our experience with band-passage experiments, described above, suggests that $\mathrm{VH}_{2}$ formation is best avoided.

Before perfecting a $\mathrm{V}-\mathrm{H}$ process, it was deemed advisable to test the dual-temperature column process on another system, Pd-H. This system has a large isotope effect which is in the opposite direction from that of vanadium; that is, the heavier isotope forms the less stable hydride. In both cases, the isotopic difference increases as the temperature is lowered, as illustrated in Figure 1. Thus, a palladium column used in a two-temperature cycle will retain tritiun in the high temperature period and release it on the low temperature side. The two types of behavior are equally suitable for a practical separation process.

A column was therefore charged with a mixture of $5 \mathrm{~g}$ palladium black and $5 \mathrm{~g}$ Chromosorb $\mathrm{W}$, of mesh size 100 to 130 . The palladium, supplied by Engelhard Industries, had a surface area of $25 \mathrm{~m}^{2} / \mathrm{g}$. The charge filled $84 \mathrm{~cm}$ of a $\frac{1}{4}-i n .-o . d$. stainless steel tube like that used for vanadium runs. 
Band-passage experiments having demonstrated chromatographic behavior but with a much shorter retention time than for vanadium, several dualtemperature runs were carried out. Figure 13 shows the record of a representative run, No. 87. The conditions were column pressure, 26 psia; temperature extremes, $0^{\circ} \mathrm{C}$ and $70^{\circ} \mathrm{C}$; flow rate of tritium-traced hydrogen, $2.5 \mathrm{cc} / \mathrm{min}$; length of half-cycle, $50 \mathrm{~min}$ on the first two cycles, $1 \mathrm{hr}$ thereafter.

Examination of the trace shows release of tritium at $70^{\circ} \mathrm{C}$ and pickup at $0^{\circ} \mathrm{C}$, as expected. Several other conspicuous differences from the vanadium results were noted. Concentration extremes were greater, breakthrough came sooner, and separative efficiency was higher. The maximum tritium concentration in the $0^{\circ} \mathrm{C}$ effluents averaged 46.5 , in the relative activity units shown on the chart; the minimum in the $70^{\circ}$ half-cycles averaged 27 units. The ratio of these numbers is 1.72 , which is the square of 1.31 , the ratio $r=\alpha_{70^{\circ}} / \alpha_{0}$. This may be compared with the value of 1.29 derivable from the $P d: \alpha_{t p}$ line of Figure 1 . The agreement is quite good.

As with vanadium, the average tritium enrichment and depletion are more important than the maxima. As described above, the areas between the halfcycle curves and a reference activity line can be used as measures of separating efficiency, or the ratios, $R$, of these areas to the area between the reference line and the time axis. 'lhe question lleu alisés, how long a timo period should be chosen? In the palladium runs, the period of effluent enrichment or depletion was always less than the pre-set 50- or 60-min duration of the half-cycle. To obtain a fair value of $R$, one should consider the half-cycle complete as soon as the effluent concentration returns to that of the input gas and calculate the reference area accordingly. Such handing of the results of run No. 87 gives the data shown in Table 5. In spite of the scatter, the separation efficiency clearly was morc than twice that of a good vanadium run.

To conclude, it is probably fair to say that our results give reason to hope that an isotope separation process based on the principle described is a real possibilicy, but thal much more research ncedo to be done before its 
economic viability can be calculated. Mòre metal hydride substrates should be tested, each under a wide range òf temperature, pressure, flow rate, particle size, etc. In recent years, isotope effects have been determined for a number of new alloy-hydrogen systems, and some of these appear quite promising for chromatographic purposes, e.g., the titanium alloys reported by Tanaka et a1. 12

We are grateful to A. Holtz for help in preparing columns, to G. Strickland for calculations of column efficiencies, and to R. Benenati and D. Mackenzie for helpful advice.

Table 5

Results of Dual-Temperature Experiment on Palladium Hydride (Run 87)

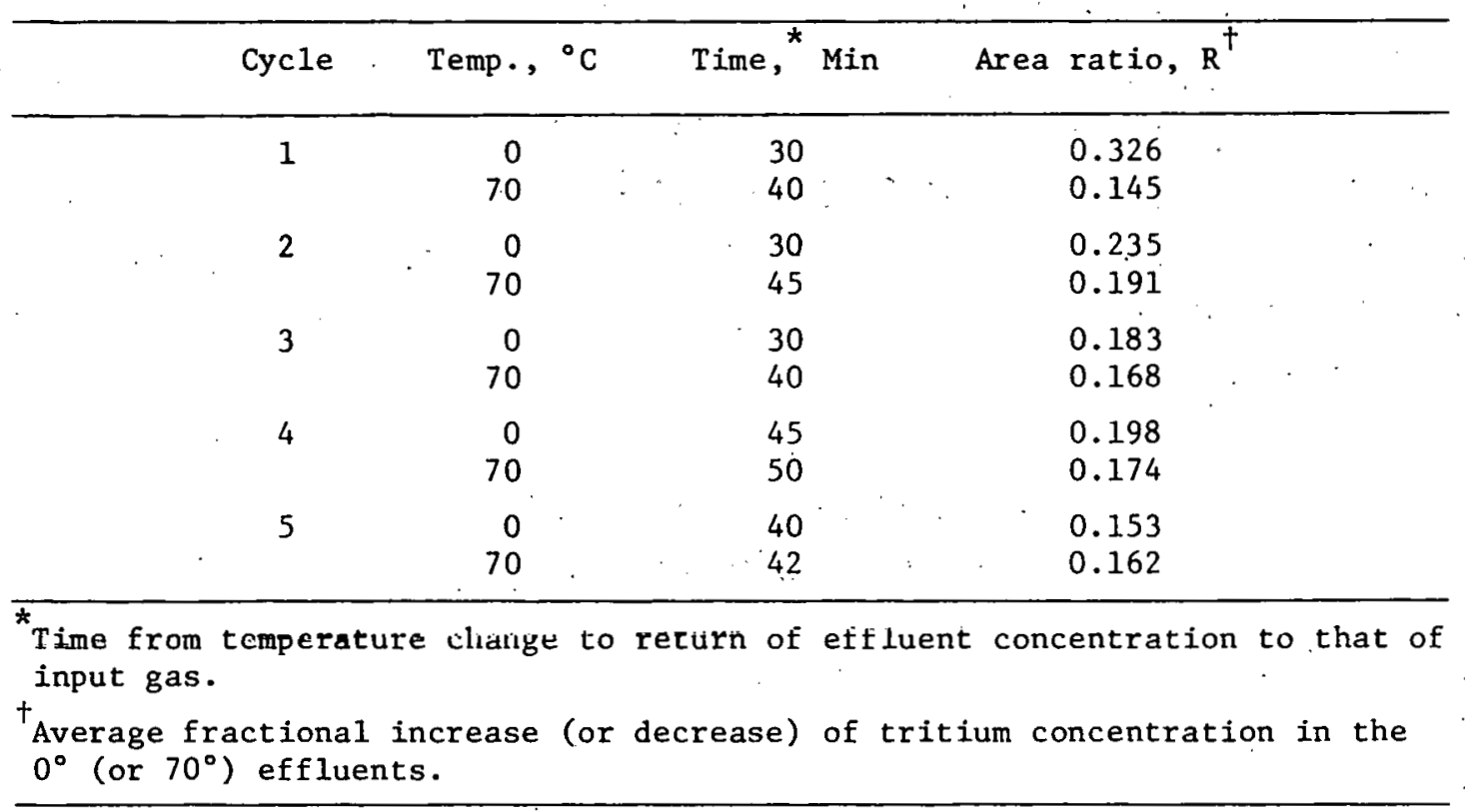




\section{REFERENCES}

1. R. H. Wiswall and J. J. Reilly, Inorg. Chem. 11, 261 (1972) .

2. R. F. Benenati, Brookhaven National Laboratory Informal Report, BNL 21294, Jan. 22, 1976.

3. C. Evans and E. J. Wilson, Report No. AERE I/M 31, March 10, 1954.

4. E. Glueckauf and G. P. Kitt, Vapour Phase Chromatography, pp 422-7,

D. H. Desty, Editor, Butterworths, London, 1957.

5. E. Glueckauf and G. P. Kitt, in Proc. Int. Symp. Isotope Separ., Amsterdam, 1957, p. 210; Interscience, New York, 1958.

6. J. Bigeleisen and A. Kant, J. Am. Chem. Soc. 6ㅜㅇ 5957 (1954).

7. E. Wicke and G. H. Nernst, Ber. Bunsenges. Phys. Chem. 68, 224 (1974).

8. J. Bigeleisen, in Tritium in the Physical and Biological Sciences (Proc. Symp. Vienna, 1961), Vol. I, pp. 161-8, IAEA, Vienna, 1962.

9. S. Dal Nogare and B. S. Juvet, Jr., Gas-Liquid Chromatography, Pp. 65-7, Interscience, New York, 1962.

10. J. J. Reilly and R. H. Wiswall, Brookhaven National Laboratory Informal Report, BNL 17136, Aug. 1, 1972.

11. J. J. Reilly and R. H. Wiswa11, Inorg. Chem. I, 2254 (1968).

12. J. Tanaka, J. J. Reilly, and R. H. Wiswall, Inorg. Chem., in press.

13. H. H. van Mal, K. H. J. Buschow, and A. R. Miedema, J. Less-Common Yel. 35, G5 (1274).

14. W. M. Mueller, J. P. Blackledge, and G. G. Libow1tz, Faltrors, Metal Hydrides, Chapter 7, Academic Press, New York, 1968.

15. J. J. Reilly and R. H. Wiswall, Inorg. Chem. 9 , 1678 (1970). 